\title{
IMPAIRED VOCAL CORD MOBILITY IN THE SETTING OF ACUTE SUPPURATIVE THYROIDITIS
}

\author{
Charles M. Boyd, MD, Ramon M. Esclamado, MD, Steve A. Telian, MD \\ Department of Otolaryngology, University of Michigan Medical Center, 1500 E. Medical Center Dr., \\ Ann Arbor, Michigan 48109
}

Received 26 February 1996; accepted 18 June 1996

\begin{abstract}
Background: Acute suppurative thyroiditis is an increasingly rare entity, accounting for less than $0.1 \%$ of thyroid surgery. This is the first report in the literature of acute thyroiditis causing a unilateral reversible vocal cord paralysis.

Methods: A 41-year-old woman was initially seen with a unilateral vocal cord paralysis resulting from acute suppurative thyroiditis.

Results: The vocal cord paralysis resolved following surgical drainage of the thyroid abscess and treatment with intravenous antibiotics.

Conclusions: We present this case to emphasize the need for a complete and thorough head and neck exam including preoperative documentation of vocal cord mobility. (c) 1997 John Wiley \& Sons, Inc. Head Neck 19: 235-237, 1997.
\end{abstract}

Keywords: acute suppurative thyroiditis; vocal cord paralysis

Acute suppurative thyroiditis is an increasingly rare entity. First described by Bauchet ${ }^{1,2}$ in 1857 , thyroid abscesses accounted for only $0.1 \%$ of thyroid surgery in the preantibiotic era. Today, with the widespread use of antibiotics, the incidence is even lower. ${ }^{1,3}$ This is the first published case of acute suppurative thyroiditis causing a unilateral, resolvable, vocal cord paralysis.

Correspondence to: C. M. Boyd

CCC 0148-6403/97/030235-03

(C) 1997 John Wiley \& Sons, Inc.

\section{CASE REPORT}

A 41-year-old woman was initially seen in the emergency room with a 10-day history of throat and neck pain, difficulty swallowing, and recent onset of hoarseness and low-grade fever. She had a 20-pack-year smoking history and only occasional alcohol use. She denied stridor, weight loss, or dyspnea on exertion. Physical exam was significant for an erythematous, warm, tender, and enlarged thyroid gland, left greater than right. There were no other peripheral stigmata of thyroid gland dysfunction. Reflexes were brisk and symmetrical. On flexible nasolaryngoscopic exam, the patient was found to have pooling of secretions in the laryngeal ventricles, fullness of the left pyriform sinus, and left vocal cord paralysis.

Laboratory studies were significant for WBC $15,600 / \mathrm{cu} \mathrm{mm}$ with $92 \%$ segmented cells, $0 \%$ bands, and 4\% lymphocytes. Calcium, phosphorous, protein, and albumin levels were normal. Thyroid function indices revealed a serum thyroxine (T4) level of $9.8 \mu \mathrm{g} / \mathrm{dL}$ (normal 4.7-12.4 $\mu \mathrm{g} / \mathrm{dL}$ ), a triiodothyronine (T3) resin uptake value of $157 \%$ (normal $86 \%$ to $114 \%$ ), a thyroxine stimulating hormone (TSH) level of $<0.2 \mu \mathrm{U} / \mathrm{ml}$ (normal 0.3-6.5 $\mu \mathrm{U}$ ), and a total (T3) level of 310 $\mathrm{ng} / \mathrm{dL}$ (normal 60-170 ng/dL). 
A computed tomographic (CT) scan of the neck demonstrated a large, multiloculated enhancing mass involving the left lobe of the thyroid gland and extending to the left aryepiglottic fold (Figure 1). The patient was taken to surgery for incision and drainage of her left thyroid abscess. A drain was left in place, and she was treated with seven days of IV antibiotics. Her cultures grew Fusobacterium nucleatum, Prevotella buccae, and numerous Bacteroides species. Vocal cord paralysis resolved during her hospital stay, and thyroid function tests returned to normal.

\section{DISCUSSION}

Thyroiditis is the infiltration of the thyroid gland by inflammatory cells. This results from a very diverse group of both infective and inflammatory diseases. Currently thyroiditis is classified in the following categories: acute suppurative, subacute granulomatous (de Quervain), subacute lymphocytic, chronic invasive fibrous (Riedel's), and chronic lymphocytic (Hashimoto's).,5 By far the rarest is acute suppurative, which is usually due to bacterial infections (68\%), followed by fungal disease $(15 \%)$, mycobacterial infections $(9.4 \%)$, parasitic infestations (5\%), and gummas (3\%)., ${ }^{2,6-9}$ The most common bacterial organisms are Group A $\beta$-hemolytic Streptococci, Staphylococci, and Pneumococci species. Additional organisms cultured from thyroid abscess cavities include $E$.

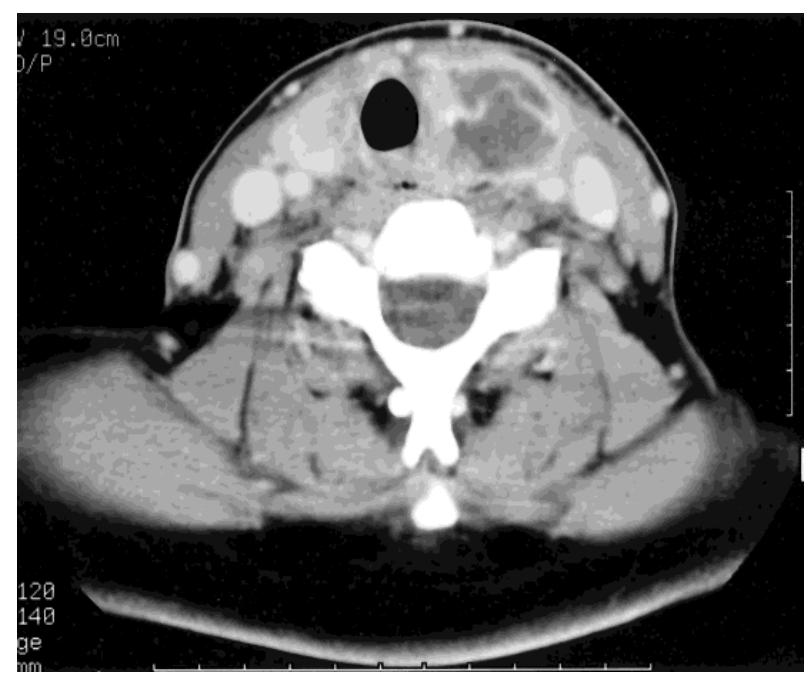

FIGURE 1. Axial CT image with contrast demonstrating a large, well-defined, multiloculated, enhancing mass involving the left lobe of the thyroid gland. The mass measured $8.5 \mathrm{~cm}$ in craniocaudal dimension, and its cross-sectional diameter was $3 \times 3 \mathrm{~cm}$. coli, Pseudomonas aeruginosa, Bacteroides melanogenicum, Hemophilus influenzae, Peptostreptococcus, Eikenella corrodens, Corynebacterium, Aspergillus fumigatas, Mycobacteriae chelonei, and Streptococcus viridans. More rarely Salmonella, syphilis, tuberculosis, actinomycosis, and bacteroides species are involved. ${ }^{2,10-15,18,19}$

Many routes of infection have been postulated: lymphatic and hematogenous, direct penetration from adjacent structures (such as fistulae arising from fourth pharyngeal pouch remnants, a persistent thyroglossal duct), or trauma. The process usually arises in a previously normal gland, not infrequently occurring in a multinodular goiter. ${ }^{3,6}$ Histologic assessment of the gland reveals a marked infiltration of polymorphonuclear leukocytes and lymphocytes in the acute phase, which may be associated with frank necrosis and abscess formation. The clinical presentation is typically a short nonspecific prodrome followed by fever, intense pain, and erythema in the area of the thyroid, resulting in dysphasia and odynophagia. Generally women between the ages of 20 and 40 years are more susceptible to thyroid suppuration, although it has been reported in all age groups and in both sexes. ${ }^{6}$ Thyroid function is usually normal, as is radioactive iodine uptake (RAIU). However, should an abscess develop, an area of decreased uptake on thyroid scan will be evident. ${ }^{6}$

The differential diagnosis includes: subacute thyroiditis, Hashimoto's thyroiditis, acute suppurative lymphadenitis, thyroid carcinoma or cyst, infected thyroglossal duct cyst or branchial cleft cyst, anterior neck abscess or cellulitis, Ludwig's angina, dissecting retropharyngeal abscess, and laryngeal carcinoma with cartilage invasion. . $^{26-9,16-18}$ These entities can usually be distinguished by history, clinical exam, and diagnostic imaging (CT or magnetic resonance imaging)

Following proper diagnosis, early initiation of intravenous antibiotics and prompt surgical drainage are key to minimizing complications. Complications can include: sepsis, tracheal or esophageal rupture, internal jugular vein thrombosis, airway obstruction, laryngeal chondritis and perichondritis, and recurrent nerve or sympathetic trunk paralysis. ${ }^{8,15-19}$ Needle aspiration can be done to confirm suppuration and provide bacteriologic information prior to imaging. Nonetheless, a CT scan is key to confirming the diagnosis, mapping the extent of neck involvement, 
assessing adjacent tissue planes, and evaluating other key structures in the neck prior to surgical intervention. ${ }^{6}$

The first step in the operating room is to control the airway. This should be accomplished by a skilled practictioner using fiberoptic intubation. Sometimes an emergent tracheotomy may be required; however, it should be avoided because it can cause aspiration of pus and mediastinitis. In most cases, the abscess can be managed with surgical drainage and thyroid biopsy, thus avoiding total or subtotal thyroidectomy in an already inflamed tissue bed. This provides adequate drainage, decreases operating room time, and avoids potential injury to the recurrent laryngeal nerves and parathyroid glands as well as the need for permanent hormone replacement therapy.

Following surgery, the patient is still at risk for thyroid and parathyroid hormone abnormalities and should be monitored with thyroid function tests and calcium levels. It is also recommended that the patient have hormone levels checked routinely for up to 1 year following the acute event. ${ }^{9}$

This case illustrates that a unilateral vocal cord paralysis can result from acute suppurative thyroiditis. The mechanism of paralysis in this case was likely due to an inflammatory neuritis or neuropraxia, although inflammatory changes of the cricoarytenoid joint is also a possibility due to the size of the abscess. To prevent the complications associated with rupture of a thyroid abscess, prompt diagnosis-including careful documentation of vocal cord function, antibiotic administration and surgical intervention, when needed-is essential.

\section{REFERENCES}

1. Mora JM. Acute thyroiditis. Am J Med Sci 1929; 178:99-105.

2. Berger SA, Zonstein J, Villamena P, Mittman N. Infectious diseases of the thyroid gland. Rev Infect Dis 1984;5:108-122.

3. Szego PL, Levy RP. Recurrent acute suppurative thyroiditis. Can Med Assoc J 1970;103:631-633.

4. Hay ID. Thyroiditis: a clinical update. Mayo Clin Proc 1985;60:836-843.

5. Helenberger JI. The various presentations of thyroiditis. Ann Int Med 1986;104:219-224.

6. Bernard PJ, Som PM, Urken ML, Lawson W, Biller HF. The CT findings of acute thyroiditis and acute suppurative thyroiditis. Otolaryngol Head Neck Surg 1988; 99:489-493.

8. Schweitzer VG, Olson NR. Thyroid abscess. Otolaryngol Head Neck Surg 1981;89:226-226.

9. Taylor WE, Myer CM, Hays LL, Cotton RT. Acute suppurative thyroiditis in children. Laryngoscope 1989; 91:1269-1273.

10. Vichyanond P, Campbell PH, Olson LC. Eikenella corrodens as a cause of thyroid abscess. Am J Dis Child 1983;137:971-973.

11. Higbee D. Acute thyroiditis in relation to deep infections of the neck. Ann Otol Rhinol Laryngol 1943;52:620627.

12. Elias AN, Kyaw T, Winikoff J, Gwinup G. Acute suppurative thyroiditis, J Otolaryngol 1985;14:17-19.

13. Taguchi T, Okuno A, Fujita K, Sanae N, Azuma H, Yoshoka $\mathrm{H}$. Etiologic factors in acute suppurative thyroiditis. J Infect Dis 1982;146:447.

14. Mann CH. Thyroid abscess in a $31 / 2$-year-old child. Arch Otolaryngol Head Neck Surg 1977;103:299-300.

15. Michel RG, Hall DM, Woodard BH. Gas-forming suppurative thyroiditis. Ear Nose Throat J 1981;60:29-33.

16. Walfish PG, Chan JYC, Ing AD. Esophageal carcinoma masquerading as recurrent acute suppurative thyroiditis. Arch Int Med 1985;145:346-347.

17. Wilson TDH, Pickard BH, Whittam DE. Carcinoma of the larynx masquerading as acute suppurative thyroiditis. Br J Surg 1969;56:936.

18. Emery P. Tuberculous abscess of the thyroid with recurrent laryngeal nerve palsy: case report and review of the literature. J Laryngol Otol 1980;94:553-558.

19. Kleinmann RE, Bagenakis AG, Abreau C. Anterior neck abscess masquerading as acute suppurative thyroiditis. J Nucl Med 1979;20:1050-1052. 